\title{
Extraction of sulfated polysaccharides by autohydrolysis of brown seaweed Fucus vesiculosus
}

\author{
Rosa M. Rodríguez-Jasso • Solange I. Mussatto • \\ Lorenzo Pastrana • Cristóbal N. Aguilar • \\ José A. Teixeira
}

Received: 13 February 2012 / Revised and accepted: 19 March 2012

(C) Springer Science+Business Media B.V. 2012

\begin{abstract}
The extraction of sulfated polysaccharides (fucoidan) by autohydrolysis (AH) of brown seaweed Fucus vesiculosus was studied. Experimental assays were performed under different conditions of temperature $\left(160\right.$ to $\left.200^{\circ} \mathrm{C}\right)$ and reaction time (10 to $30 \mathrm{~min}$ ) according to a $2^{2}$ central composite design, and the conditions able to maximize the fucoidan yield were selected. The alga degradation and the total sugar yield in the liquor after $\mathrm{AH}$ were also determined to each experimental condition. The highest fucoidan yield $(\sim 16.5 \% w / w)$ was obtained when the $\mathrm{AH}$ process was performed at $180^{\circ} \mathrm{C}$ for $20 \mathrm{~min}$. This product was characterized by high-performance liquid chromatography, infrared analysis spectroscopy, and thermal gravimetric analyses, which verified the presence of fucose and galactose as main components (70:30\% mol ratio, in average) and an $\mathrm{SO}_{3}$ content higher than $20 \%$. AH process under optimum reaction conditions was an effective method to recover fucoidan from $F$. vesiculosus. The use of this technology brings also
\end{abstract}

R. M. Rodríguez-Jasso $\cdot$ S. I. Mussatto $(\bowtie) \cdot J$. A. Teixeira Institute for Biotechnology and Bioengineering (IBB), Centre of Biological Engineering, University of Minho, Campus de Gualtar, 4710-057 Braga, Portugal

e-mail: solange@deb.uminho.pt

S. I. Mussatto

e-mail: solangemussatto@hotmail.com

L. Pastrana

Department of Biochemistry, Genetics and Immunology,

University of Vigo,

Ourense, 32004 Galicia, Spain

C. N. Aguilar

Department of Chemical Engineering, School of Chemistry,

Autonomous University of Coahuila,

25280 Saltillo, Coahuila, Mexico important advantages from economical and environmental viewpoints since it does not require the use of chemical solvent and generates less waste when compared to conventional extraction procedures.

Keywords Algae - Fucus vesiculosus · Autohydrolysis . Sulfated polysaccharides $\cdot$ Optimization

\section{Introduction}

In recent years, great attention has been given to the use of marine seaweed biomass. Such interest has been supported by important advantages that the use of this kind of biomass represents: (a) low future fluctuations in biomass demand are expected due to overpopulation; (b) feasibility of growing fast in the open ocean; (c) higher photosynthetic efficiency than terrestrial biomass; (d) no limitation by water and to a lesser extent by temperature; and (e) low costs of collection (Ross et al. 2008; Anastasakis et al. 2011). Main components of marine seaweeds differ from that of terrestrial biomass (cellulose, hemicellulose, and lignin) and include phytochemically active molecules such as polysaccharides, fatty acids, proteins, vitamins, and mineral elements, which are compounds with potential applications in food, cosmetic, pharmaceutical, and medical fields (O'Sullivan et al. 2010; Anastasakis et al. 2011; Lordan et al. 2011).

Brown seaweed-derived polysaccharides such as fucoidan, laminaran, alginates, and mannitol have been studied due to their effectiveness as anticoagulant, antitumor, antithrombotic, anti-inflammatory, contraceptive, and antiviral agent (Bhakuni and Rawat 2005; Imbs et al. 2009; Wang et al. 2009; Mestechkina and Shcherbukhin 2010). Fucoidans, or sulfated fucans, may constitute up to $25-30 \%$ of the seaweed dry weight, depending on the seaweed species and, 
to a lesser extent, on life history stage and season (Kusaykin et al. 2008). The most relevant biological functionalities of these compounds are the activities against hepatitis, herpes, and human immunodeficiency (AIDS) viruses, anticoagulant heparin inflammation, cell proliferation and adhesion, and fertilization functions (Ellouali et al. 1993; Berteau and Mulloy 2003; Queiroz et al. 2008).

The extraction of sulfated polysaccharides from seaweeds has been usually performed by using hot water, dilute acid, or dilute alkali-all of these methodologies involve long extraction time and high volume of diluents (Duarte et al. 2001; Marais and Joseleau 2001; Rioux et al. 2007; Yang et al. 2008; Skriptsova et al. 2010). Among the existing technologies of hydrolysis, the autohydrolysis (AH) is an eco-friendly process that could be an interesting alternative for application on the recovery of biological compounds from seaweeds. This process requires only the use of water as extraction solvent, and the hydronium-catalyzed reactions of the material fibers proceed through water autoionization at elevated temperatures $\left(150-230^{\circ} \mathrm{C}\right)$. This process offers several important advantages, such as: (1) simple and economical operation; (2) elimination of corrosive problems; (3) mild operational conditions for selective degradation of the biomass; and (4) generation of low concentrations of sugar degradation products in the media (Garrote et al. 1999).

Despite of all the above-mentioned benefits, research on the application of AH process to macroalgae is limited. The aim of the current study was to evaluate the extraction of sulfated polysaccharides (fucoidan) by AH of brown seaweed Fucus vesiculosus. An experimental design was proposed to evaluate the effect of the process variables (temperature and reaction time) on the responses: fucoidan yield, alga degradation, and total sugar yield in the liquor after extraction. The product obtained was characterized to determine the monosaccharide and sulfate contents. Infrared analysis spectroscopy and thermal gravimetric analyses were also performed to explain the characteristics of the extracted fucoidan.

\section{Materials and methods}

3,5-Dinitrosalicylic acid was purchased from Fluka, Chemika; anthrone reagent was from Prolabo, Normapur, Merck; and Coomassie Plus (Bradford) Assay Kit was obtained from Thermo Scientific Co. Other reagents were all of analytical grade.

Samples of $F$. vesiculosus were collected from Praia Norte (Viana do Castelo, Portugal) during the spring season (May 2010). The seaweed was washed with fresh water in order to remove salt, sand, and epiphytes, dried at $35^{\circ} \mathrm{C}$, milled in a home blender, and stored in plastic bags at room temperature. Particles lower than 1,000 $\mu$ m were not used in the experiments. The seaweed sample had moisture and ash contents of $14.84 \pm 0.83 \%(w / w)$ and $17.5 \pm 0.25 \%(w / w)$, respectively (dry weight basis).

\section{Autohydrolysis process}

For the extraction of sulfated polysaccharides from $F$. vesiculosus, $2 \mathrm{~g}$ of milled seaweed was suspended in $50 \mathrm{~mL}$ of distilled water (alga/water ratio of 1:25), and the mixture was placed in $160-\mathrm{mL}$ stainless steel cylinder reactors, which were submerged in an oil bath with open heating circulator (Julabo Labortechnik GmbH, Germany) and PID temperature control. The autohydrolysis process was carried out under different conditions of temperature and reaction time (Table 1). At the end of the reaction, the reactors were removed from the oil bath and immediately immersed in an ice bath to stop the reaction. The obtained suspension was vacuum-filtrated to separate the liquor from the residual alga, which was dried at $35^{\circ} \mathrm{C}$, weighed to determine the percentage of alga degradation $\left(\% \mathrm{AD}_{\mathrm{AH}}\right)$, and stored. Total sugar yield in the liquor after $\mathrm{AH}\left(\% \mathrm{TS}_{\mathrm{LAH}}\right)$ was quantified, and subsequently, a $1 \%(w / v)$ solution of $\mathrm{CaCl}_{2}$ was added to the liquor in a ratio of $1: 1(\mathrm{v} / \mathrm{v})$ for alginate removal $\left(4^{\circ} \mathrm{C}\right.$ overnight storage). Free alginate liquor was recovered by filtration in qualitative paper, and then double volume of ethanol absolute was added to the resultant filtrate, and the mixture was stored at $4^{\circ} \mathrm{C}$ for $8 \mathrm{~h}$. The precipitated polysaccharide $\left(\% \mathrm{Fuc}_{\mathrm{AH}}\right)$ was recovered by centrifugation $\left(8,500 \mathrm{rpm}, 15 \mathrm{~min}, 4^{\circ} \mathrm{C}\right)$, dried at $35^{\circ} \mathrm{C}$, milled, and stored for analyses. Two replicates of each experiment were carried out.

The fucoidan yield $\left(\% \mathrm{Fuc}_{\mathrm{AH}}\right)$, alga degradation $\left(\% \mathrm{AD}_{\mathrm{AH}}\right)$, and total sugar yield in the liquor after extraction $\left(\% \mathrm{TS}_{\mathrm{LAH}}\right)$ were calculated by using Eqs. (1), (2), and (3), where $\mathrm{WM}_{\mathrm{OH}}$ is the dry mass weight obtained after ethanol precipitation; WA is the alga weight used in each experiment; $\mathrm{WA}_{\mathrm{AH}}$ is the dry alga weight recovered after $\mathrm{AH}$; $\mathrm{TS}_{\mathrm{AH}}$ is the mg of total sugar in the hydrolysates obtained after $\mathrm{AH}$; and $\mathrm{TS}_{\mathrm{A}}$ is the $\mathrm{mg}$ of total sugars in the alga $F$. vesiculosus (35.12 $\mathrm{mg} \mathrm{TS} / 100 \mathrm{mg}$ alga).

$$
\begin{aligned}
& \% \mathrm{Fuc}_{\mathrm{AH}}=\frac{\mathrm{WM}_{\mathrm{OH}}}{\mathrm{WA}} \times 100 \\
& \% \mathrm{AD}_{\mathrm{AH}}=\left(\frac{\mathrm{WA}-\mathrm{WA}_{\mathrm{AH}}}{\mathrm{WA}}\right) \times 100 \\
& \mathrm{OTS}_{\mathrm{LAH}}=\left(\frac{\mathrm{TS}_{\mathrm{AH}}}{\mathrm{TS}_{\mathrm{A}}}\right) \times 100
\end{aligned}
$$


Table 1 Values of the process variables, severity factor $\left(\log R_{0}\right)$, and results of fucoidan yield $\left(\% \mathrm{Fuc}_{\mathrm{AH}}\right)$, alga degradation $\left(\% \mathrm{AD}_{\mathrm{AH}}\right)$, and total sugar yield in the liquor after extraction $\left(\% \mathrm{TS}_{\mathrm{LAH}}\right)$, to each experimental condition used for autohydrolysis of Fucus vesiculosus

${ }^{\mathrm{a}}$ The severity parameter of the autohydrolysis process was calculated by Eq. (4)

\begin{tabular}{|c|c|c|c|c|c|c|c|}
\hline \multicolumn{3}{|c|}{ Process variables — real and (coded) values } & \multirow[b]{2}{*}{$\log R_{0}{ }^{\mathrm{a}}$} & \multirow[b]{2}{*}{ Final $\mathrm{pH}$} & \multicolumn{3}{|l|}{ Responses } \\
\hline Run & Temperature $\left({ }^{\circ} \mathrm{C}\right)$ & Reaction time (min) & & & $\% \mathrm{Fuc}_{\mathrm{AH}}$ & $\% \mathrm{AD}_{\mathrm{AH}}$ & $\% \mathrm{TS}_{\mathrm{LAH}}$ \\
\hline 1 & $200(+1)$ & $30(+1)$ & 4.4 & 4.90 & $4.58 \pm 1.31$ & $30.52 \pm 1.45$ & $14.49 \pm 0.72$ \\
\hline 2 & $200(+1)$ & $10(-1)$ & 4.0 & 6.57 & $8.22 \pm 1.07$ & $61.62 \pm 5.39$ & $8.62 \pm 1.20$ \\
\hline 3 & $160(-1)$ & $10(-1)$ & 2.8 & 6.79 & $3.23 \pm 0.08$ & $73.82 \pm 2.60$ & $3.66 \pm 0.17$ \\
\hline 4 & $160(-1)$ & $30(+1)$ & 3.2 & 6.31 & $6.05 \pm 1.14$ & $61.42 \pm 0.46$ & $11.06 \pm 2.16$ \\
\hline 5 & $180(0)$ & $10(-1)$ & 3.4 & 6.73 & $5.68 \pm 0.32$ & $66.32 \pm 4.46$ & $6.47 \pm 0.72$ \\
\hline 6 & $180(0)$ & $30(+1)$ & 3.8 & 5.13 & $8.42 \pm 1.49$ & $34.09 \pm 0.83$ & $14.92 \pm 0.12$ \\
\hline 7 & $200(+1)$ & $20(0)$ & 4.3 & 5.01 & $7.16 \pm 0.87$ & $32.67 \pm 1.84$ & $11.38 \pm 1.67$ \\
\hline 8 & $160(-1)$ & $20(0)$ & 3.1 & 6.52 & $7.16 \pm 0.86$ & $61.55 \pm 3.54$ & $7.16 \pm 0.31$ \\
\hline 9 & $180(0)$ & $20(0)$ & 3.7 & 6.15 & 18.14 & 47.35 & 13.35 \\
\hline 10 & $180(0)$ & $20(0)$ & 3.7 & 6.20 & 16.57 & 45.77 & 14.89 \\
\hline 11 & $180(0)$ & $20(0)$ & 3.7 & 6.09 & 15.34 & 43.67 & 13.98 \\
\hline 12 & $180(0)$ & $20(0)$ & 3.7 & 6.41 & 15.88 & 44.25 & 15.89 \\
\hline
\end{tabular}

The severity parameter $\left(\log R_{0}\right)$ of the $\mathrm{AH}$ process was calculated by Eq. (4) (Overend and Chornet 1987), where $t$ is the time $(\mathrm{min})$ at the temperature of reaction $T\left({ }^{\circ} \mathrm{C}\right)$, and 14.75 is an empirical parameter related with the temperature and activation energy.

$R_{0}=\int_{0}^{t} \exp \left[\frac{T(t)-100}{14.75}\right] d t$

In a subsequent step, sequential extraction assays were performed aiming to verify the possibility of reusing the residual alga (after the AH process) to maximize the fucoidan recovery yield. Sequential extraction procedures were performed under the previously established $\mathrm{AH}$ conditions $\left(180^{\circ} \mathrm{C}, 20 \mathrm{~min}\right)$, following the same procedure described above. After the first extraction (E1), the residual solid material was separated by filtration, resuspended in distilled water to reach the alga/water ratio of 1:25 $(w / v)$, and hydrolyzed again (E2) in the oil bath system.

\section{Analytical procedures}

For characterization of the recovered fucoidan, samples of $10-15 \mathrm{mg}$ of the fucoidan extracts were hydrolyzed with $4 \mathrm{~N} \mathrm{HCl}(2 \mathrm{~mL})$ at $121^{\circ} \mathrm{C}$ for $2 \mathrm{~h}$. The total sugar content was then measured by the anthrone method using glucose as standard (Ludwig and Goldberg 1954), and the sulfate group content was determined by turbidity with barium chloride-gelatin method (Dodgson 1961). All absorbance measurements were carried out in triplicate. Protein was determined by the method of Bradford (1976) and the total phenolic compounds by the method of Folin-Ciocalteau.

The concentration of monosaccharides was determined by hydrolysis of the fucoidan samples $(10-15 \mathrm{mg})$ with $2 \mathrm{M}$ trifluoroacetic acid $(0.5 \mathrm{~mL})$ at $121^{\circ} \mathrm{C}$ for $2 \mathrm{~h}$, in glass tubes sealed with $\mathrm{N}_{2}$. Hydrolyzed polysaccharides were cooled in an ice water bath, centrifuged at 5,000 rpm for $5 \mathrm{~min}$, and the liquid fraction was neutralized to $\mathrm{pH} 7$ with $2 \mathrm{M} \mathrm{NaOH}$. The resulting samples were injected in a high-performance liquid chromatography (Jasco, Japan) system equipped with a low-pressure gradient solvent pump, an autosampler with $20-\mu l$ loop, and a refraction index detector (Jasco, Tokyo, Japan). Samples were injected in a MetaCarb $67 \mathrm{H}(300 \times$ $7.8 \mathrm{~mm}$ ) column at $60^{\circ} \mathrm{C}$, using $0.005 \mathrm{M} \mathrm{H}_{2} \mathrm{SO}_{4}$ as mobile phase at a flow rate of $0.5 \mathrm{~mL} \mathrm{m^{-1 }}$. Micrographs of the seaweed samples were obtained in a scanning electron microscope Nova NanoSEM 200 (Netherlands) using the samples sputtered with gold under high-vacuum conditions and an accelerating voltage of approximately $15 \mathrm{kV}$.

Thermal gravimetric analysis (TGA) was performed in a thermo gravimetric analyzer model TGA-50 (Shimadzu Corporation, Japan) under nitrogen atmosphere. Differential scanning calorimetry (DSC) analysis was performed using a Modulate DSC-50 (Shimadzu Corporation, Japan). Mass samples of $10-13 \mathrm{mg}$ were run from room temperature to $600^{\circ} \mathrm{C}$ at a rate of $10^{\circ} \mathrm{C} \mathrm{m^{-1 }}$.

Infrared analysis spectroscopy (FTIR) was carried out on a Perkin-Elmer 16 PC spectrometer, using 16 scans and frequency range of $400-4,000 \mathrm{~cm}^{-1}$. For the analysis, the polysaccharide was ground with potassium bromide powder and then pressed into 1-mm pellets. The vibration transition frequencies of each spectrum were baseline corrected and the absorbance was normalized between 0 and 1 .

Experimental design and data analysis

The effects of the independent variables, temperature $\left(X_{1}\right.$, $\left.{ }^{\circ} \mathrm{C}\right)$ and residence time $\left(X_{2}, \mathrm{~min}\right)$, on the extraction of fucoidan by $\mathrm{AH}$ were evaluated through a $2^{2}$ central composite design with four replicates at the center point. 
The variables were coded according to Eq. (5), where $x_{i}$ is the coded value of the variable $X_{i}, X_{0}$ is the value of $X_{i}$ at the center point, and $\Delta X_{i}$ is the step change. The real and coded values of the variables are shown in Table 1. Experimental runs were randomized to minimize the effects of unexpected variability in the responses.

$x_{\mathrm{i}}=\left(X_{\mathrm{i}}-X_{0}\right) / \Delta X_{\mathrm{i}}$

The fucoidan yield $\left(\% \mathrm{Fuc}_{\mathrm{AH}}\right)$, alga degradation $\left(\% \mathrm{AD}_{\mathrm{AH}}\right)$, and total sugar yield in the liquor after extraction $\left(\% \mathrm{TS}_{\mathrm{LAH}}\right)$ were taken as responses of the experimental design. The results were analyzed by analysis of variance, and the behavior of the system was explained by Eq. (6), where $Y$ is the dependent variable, $\beta_{0}$ is constant, $\beta_{i}, \beta_{i i}$, and $\beta_{i j}$ are the coefficients estimated by the model, and $X_{i}$ and $X_{j}$ are the levels of the independent variables. Analyses of the experimental data were carried out using the software STATISTI$\mathrm{CA}^{\mathrm{TM}}$ v 6.0 (Statsoft ${ }^{\circledR}$, USA).

$Y=\beta_{0}+\sum_{i=1}^{n} \beta_{i} X_{i}+\sum_{i=1}^{n} \beta_{i i} X_{i}^{2}+\sum_{i=1}^{n-1} \sum_{j=i+1}^{n} \beta_{i j} X_{i} X_{j}$

\section{Results and discussion}

\section{Sulfated polysaccharides yields}

The fucoidan yield $\left(\% \mathrm{Fuc}_{\mathrm{AH}}\right)$, alga degradation $\left(\% \mathrm{AD}_{\mathrm{AH}}\right)$, and total sugar yield in the liquor after extraction $\left(\% \mathrm{TS}_{\mathrm{LAH}}\right)$ to each experimental AH condition are shown in Table 1. As can be seen, great variations occurred in all these responses according to the used process condition. The fucoidan yield, for example, was increased when the value of the severity factor $\left(\log R_{0}\right)$ was increased, but up to a certain limit $\left[\log R_{0}=3.7\left(180^{\circ} \mathrm{C}\right.\right.$ and $20 \mathrm{~min}$; runs $\left.9-12\right)-\% \mathrm{Fuc}_{\mathrm{AH}}=$ $15-18 \% w / w]$; after which, a significant lost of yield was observed $\left[\log R_{0}=4.4\left(200^{\circ} \mathrm{C}\right.\right.$ and $30 \mathrm{~min}$; run 1$)-\% \mathrm{Fuc}_{\mathrm{AH}}=$ $4.6 \% \mathrm{w} / \mathrm{w}]$. The $\mathrm{pH}$ decrease observed in the reaction media obtained by using the highest values of severity factor may have affected the fucoidan recovery, since acid media could have favored the hydrolysis of this polysaccharide, causing a decrease in the final recovery yield.

The highest values of total sugar yield in the liquor $(>14 \% w / w)$ were obtained when using $\log R_{0}$ similar or higher than 3.7. This result suggests that the sugars obtained at $180^{\circ} \mathrm{C}$ for $20 \mathrm{~min}$ (runs 9-12) probably are polysaccharides of long chain able to agglomerate and precipitate as sulfated fucans, causing an elevated fucoidan recovery yield. On the contrary, it is also possible that the total sugars obtained at $200^{\circ} \mathrm{C}$ for $30 \mathrm{~min}$ (run 1) are mainly monosaccharide and/or short chain polysaccharides, explaining the low recovery yield.

The effect of the AH process over brown seaweed fucoidan may be attributed to the heterogeneous backbone structure of this molecule, with alternating $(1 \rightarrow 3)$ and $(1 \rightarrow 4)$ linked 2- and/or 4-sulfated- $\alpha$-L-Fuc $\rho$ residues. The depolymerization of this structure affects the $(1 \rightarrow 3)-\alpha$-L-Fuc $\rho$ residues faster than the $(1 \rightarrow 4)-\alpha$-L-Fuc $\rho$ residues, causing intermolecular changes with transference of the sulfate groups to pentose and hexose sugars, which allow obtaining polysaccharides and oligosaccharides of multisulfated (up to three) fucans (Anastyuk et al. 2010). Therefore, all the fucoidan samples recovered in the current study presented high sulfate content $(>18 \%)$.

The highest fucoidan yield $(\sim 16.5 \% \mathrm{w} / \mathrm{w})$ obtained in the present study was similar to the values reported by microwave-assisted extraction of $F$. vesiculosus (RodriguezJasso et al. 2011) and was higher than the values reported by diluted $\mathrm{HCl}$ treatment of Laminaria cichorioides (Anastyuk et al. 2010) or by sequential extraction with $\mathrm{CaCl}_{2}$ and $\mathrm{HCl}$ from either F. vesiculosus, Ascophyllum nodosum, or Saccharina longicruris (Rioux et al. 2007). In the last cases, besides the higher yield, AH has also other important advantages when

Table 2 Effect estimates (EE), standard errors (SE), and level of significance $(p)$ for the responses of fucoidan yield (\%Fuc $\left.\mathrm{AH}_{\mathrm{H}}\right)$, alga degradation $\left(\% \mathrm{AD}_{\mathrm{AH}}\right)$, and total sugar yield in the liquor after extraction $\left(\% \mathrm{TS}_{\mathrm{LAH}}\right)$, obtained by autohydrolysis of Fucus vesiculosus

\begin{tabular}{|c|c|c|c|c|c|c|}
\hline \multirow[t]{2}{*}{ Variables } & \multicolumn{2}{|l|}{$\% \mathrm{Fuc}_{\mathrm{AH}}$} & \multicolumn{2}{|l|}{$\% \mathrm{AD}_{\mathrm{AH}}$} & \multicolumn{2}{|l|}{$\% \mathrm{TS}_{\mathrm{LAH}}$} \\
\hline & $\mathrm{EE} \pm \mathrm{SE}$ & $p$ & $\mathrm{EE} \pm \mathrm{SE}$ & $p$ & $\mathrm{EE} \pm \mathrm{SE}$ & $p$ \\
\hline$x_{1}$ & $1.17 \pm 2.34$ & 0.634 & $-23.99 \pm 2.94$ & $0.000^{\mathrm{b}}$ & $4.20 \pm 1.31$ & $0.019^{\mathrm{a}}$ \\
\hline$x_{1}^{2}$ & $-10.85 \pm 3.51$ & $0.021^{\mathrm{a}}$ & $8.49 \pm 4.42$ & 0.103 & $-6.50 \pm 1.97$ & $0.017^{\mathrm{a}}$ \\
\hline$x_{2}$ & $0.64 \pm 2.34$ & 0.793 & $-25.24 \pm 2.94$ & $0.000^{\mathrm{b}}$ & $7.24 \pm 1.31$ & $0.001^{\mathrm{b}}$ \\
\hline$x_{2}^{2}$ & $-11.07 \pm 3.51$ & $0.020^{\mathrm{a}}$ & $14.68 \pm 4.42$ & $0.016^{\mathrm{a}}$ & $-3.65 \pm 1.97$ & 0.114 \\
\hline$x_{1} x_{2}$ & $-3.23 \pm 2.87$ & 0.303 & $-9.35 \pm 3.60$ & $0.041^{\mathrm{a}}$ & $-0.77 \pm 1.61$ & 0.651 \\
\hline
\end{tabular}

$x_{1}$ temperature, $x_{2}$ reaction time

${ }^{a} 95 \%$, significance level

b $99 \%$, significance level 
Fig. 1 Response surface fitted to the experimental data points corresponding to the fucoidan yield during autohydrolysis of F. vesiculosus under different conditions of temperature and reaction time

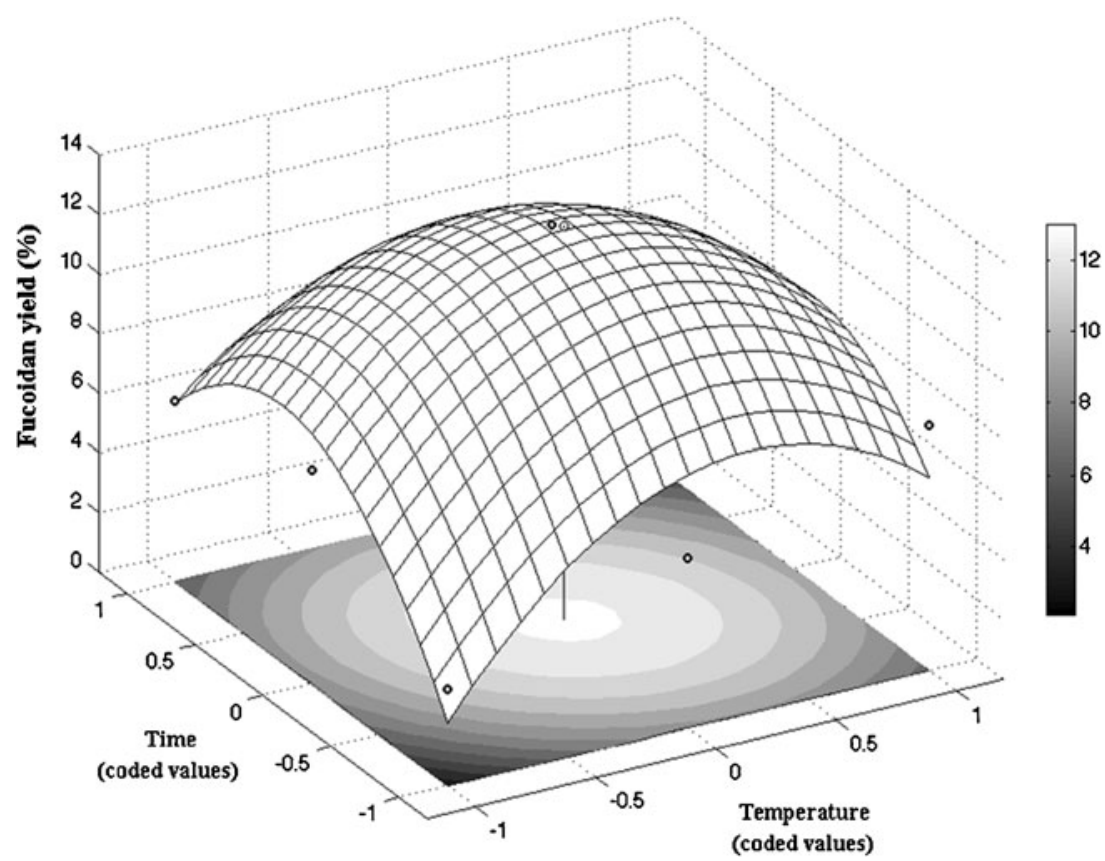

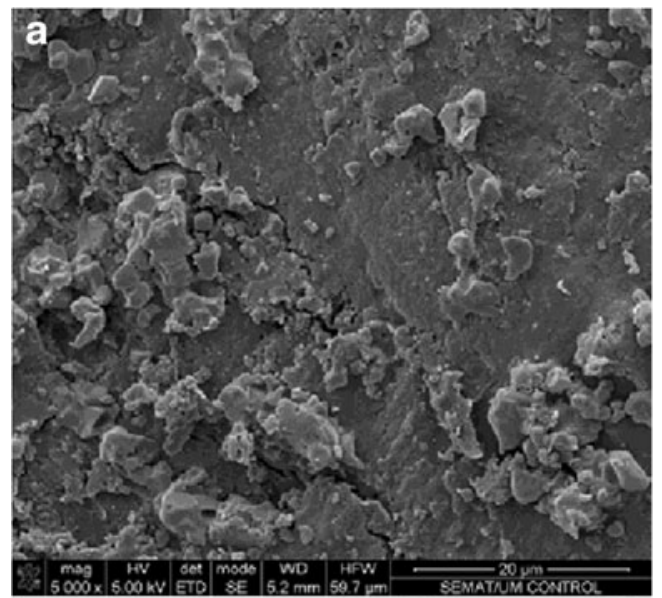

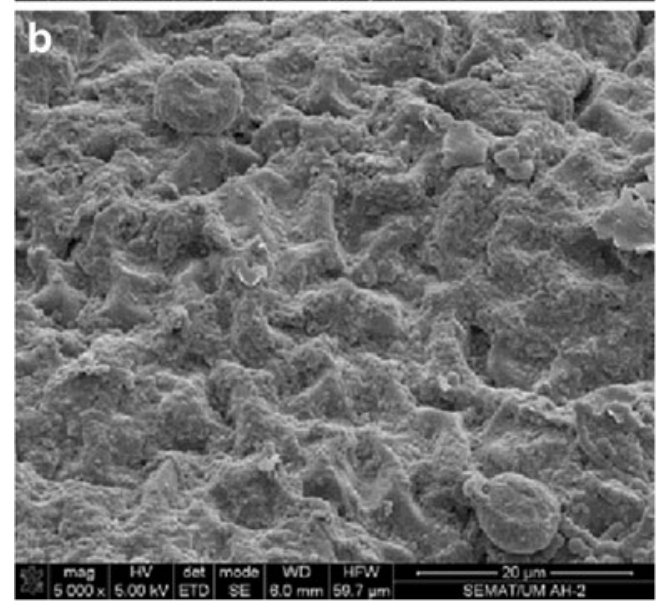

Fig. 2 Scanning electron micrographs of $F$. vesiculosus: a untreated sample; b residual sample obtained after autohydrolysis at $180^{\circ} \mathrm{C}$ for 20 min. Magnification $\times 5,000$-fold compared to these extraction methods. Since it does not require the use of chemicals as an extraction solvent, it is more environmentally friendly, easier to operate, and does not cause corrosion problems in the equipment (Garrote et al. 1999). On the other hand, when compared to microwaveassisted extraction, which also used only water as extraction solvent and promoted similar fucoidan extraction yield in a short time of process ( $1 \mathrm{~min}$ ), an economical analysis would be useful to verify if AH would be more economically viable to extract fucoidan from brown seaweed. In any way, $\mathrm{AH}$ could be more easily used on an industrial scale, while the scale-up of microwave-assisted extraction systems is an important barrier to be overcome for its industrial application (Mandal et al. 2007).

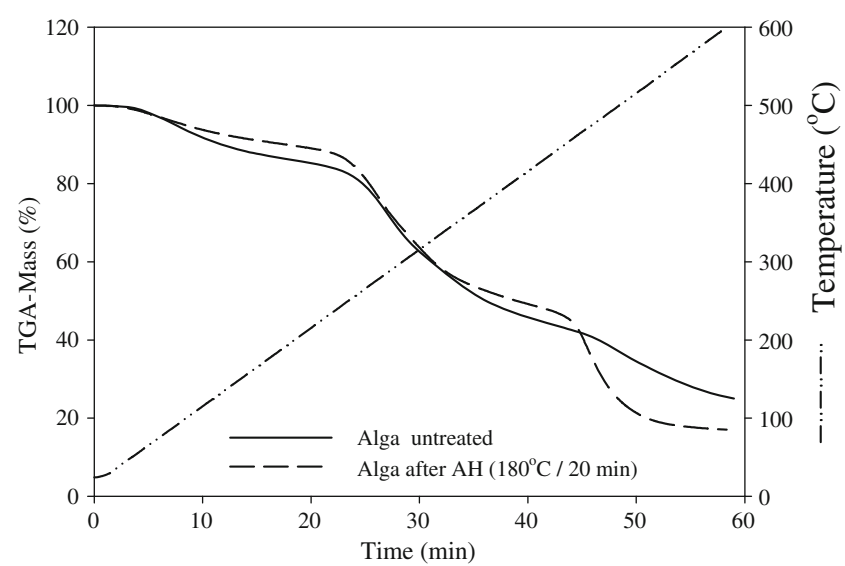

Fig. 3 TGA of $F$. vesiculosus before and after the autohydrolysis process under optimized reaction conditions $\left(180^{\circ} \mathrm{C}, 20 \mathrm{~min}\right)$ 
Table 3 Chemical composition of fucoidan samples recovered by autohydrolysis of Fucus vesiculosus under different operational conditions

\begin{tabular}{|c|c|c|c|c|c|c|c|c|}
\hline \multirow[t]{2}{*}{ Run } & \multicolumn{2}{|c|}{ Autohydrolysis condition } & \multicolumn{6}{|c|}{ Fucoidan composition } \\
\hline & Temperature $\left({ }^{\circ} \mathrm{C}\right)$ & Time (min) & Fucose $(\% \mathrm{~mol})$ & Galactose $(\% \mathrm{~mol})$ & $\mathrm{SO}_{3}(\%)$ & $\mathrm{TS} / \mathrm{SO}_{3}{ }^{\mathrm{a}}\left(\mathrm{mol} \mathrm{mol}^{-1}\right)$ & Protein $\left(\mathrm{mg} \mathrm{L}^{-1}\right)$ & Phenols ${ }^{\mathrm{b}}(\%)$ \\
\hline 1 & 200 & 30 & 52.21 & 47.79 & $\begin{array}{c}30.78 \pm \\
2.13\end{array}$ & $1 / 1.82$ & $5.55 \pm 1.03$ & $3.15 \pm 0.53$ \\
\hline 2 & 200 & 10 & 83.96 & 16.04 & $\begin{array}{c}21.02 \pm \\
2.33\end{array}$ & $1 / 0.96$ & $5.11 \pm 0.83$ & $3.69 \pm 0.16$ \\
\hline 3 & 160 & 10 & 81.16 & 18.84 & $\begin{array}{c}23.67 \pm \\
1.40\end{array}$ & $1 / 1.33$ & $4.97 \pm 0.17$ & $4.84 \pm 0.16$ \\
\hline 4 & 160 & 30 & 75.08 & 24.92 & $\begin{array}{c}25.59 \pm \\
2.42\end{array}$ & $1 / 1.14$ & $5.51 \pm 0.31$ & $5.38 \pm 0.06$ \\
\hline 5 & 180 & 10 & 74.12 & 25.88 & $\begin{array}{c}22.08 \pm \\
1.16\end{array}$ & $1 / 0.95$ & $10.39 \pm 2.13$ & $3.95 \pm 0.21$ \\
\hline 6 & 180 & 30 & 55.14 & 44.86 & $\begin{array}{c}20.96 \pm \\
2.51\end{array}$ & $1 / 0.79$ & $10.90 \pm 1.00$ & $4.87 \pm 0.46$ \\
\hline 7 & 200 & 20 & 51.79 & 48.21 & $\begin{array}{c}19.06 \pm \\
0.44\end{array}$ & $1 / 1.00$ & $12.41 \pm 0.36$ & $3.99 \pm 0.91$ \\
\hline 8 & 160 & 20 & 77.75 & 22.25 & $\begin{array}{c}18.46 \pm \\
0.66\end{array}$ & $1 / 1.08$ & $9.21 \pm 1.37$ & $3.35 \pm 0.01$ \\
\hline $9-12^{\mathrm{c}}$ & 180 & 20 & 76.76 & 23.24 & $\begin{array}{c}21.21 \pm \\
0.76\end{array}$ & $1 / 0.87$ & $8.56 \pm 0.57$ & $5.63 \pm 0.78$ \\
\hline
\end{tabular}

Monosaccharide amounts are expressed as the percent of total sugar content in the sample

$T S$ total sugars

${ }^{\mathrm{a}} \mathrm{TS} / \mathrm{SO}_{3}=(\mathrm{mg} \mathrm{TS} / 100 \mathrm{mg}$ fucoidan $) /(\mathrm{mg} \mathrm{SO} / 100 \mathrm{mg}$ fucoidan $)$

${ }^{\mathrm{b}} \mathrm{mg}$ of total phenols/100 $\mathrm{mg}$ of fucoidan

${ }^{\mathrm{c}}$ Mean value of four center point assays

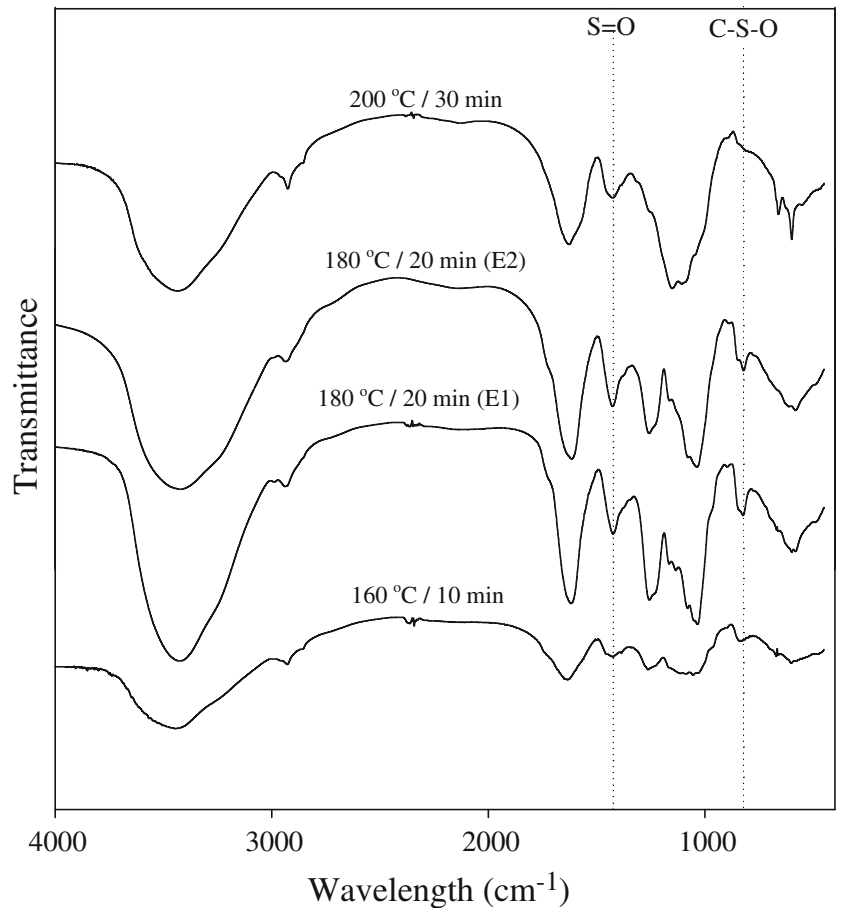

Fig. 4 FTIR of fucoidan samples obtained by autohydrolysis of $F$. vesiculosus under different operational conditions
Statistical analysis and optimization of autohydrolysis conditions

The effect estimates of the operational variables as well as their significance level on the responses are shown in Table 2 . As can be noted, the studied variables significantly affected all the responses, presenting individual (first and second order) and/or interaction effects. A threedimensional response surface was plotted in order to

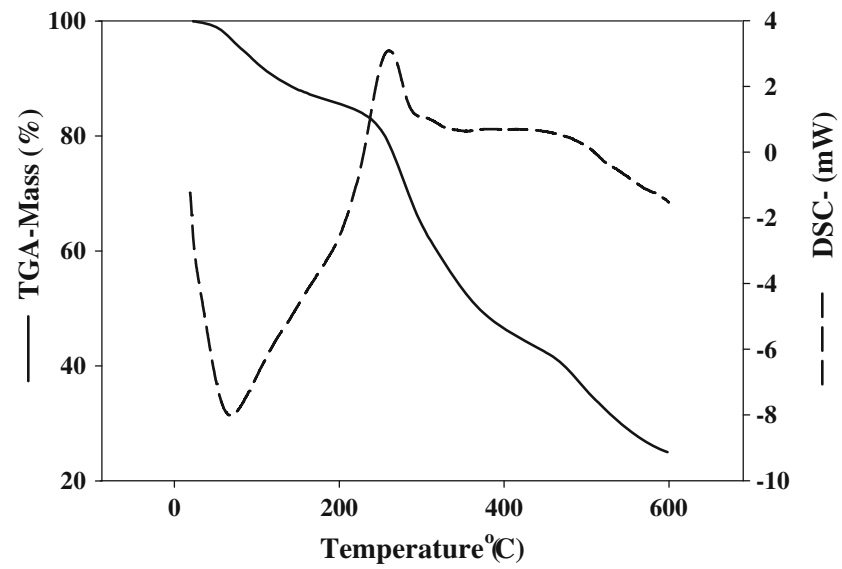

Fig. 5 TGA and DSC of the fucoidan sample recovered under the optimized autohydrolysis conditions $\left(180^{\circ} \mathrm{C}, 20 \mathrm{~min}\right)$ 
represent the fucoidan yield variations as a function of the temperature and reaction time variations. This figure (Fig. 1) clearly shows that the fucoidan yield was not linearly increased when the process variables were increased, but there was an optimum point after which the use of higher temperature and reaction time did not improve the yield. This is in agreement with the analysis presented in Table 2, which revealed significant effect of the quadratic term of both variables on the fucoidan yield response. An estimate of the critical point revealed that $180^{\circ} \mathrm{C}$ and $20 \mathrm{~min}$ were the conditions able to maximize the fucoidan yield.

The alga degradation and the total sugar yield in the liquor after extraction were also affected by the quadratic terms of the variables (Table 2). This fact suggests that similar to the observed for the fucoidan yield, the variation of these responses did not occur linearly by increasing the value of the variables. A regression analysis was then performed to fit equations able to predict the value of the responses according to the temperature and reaction time variations used in the present study. The mathematical models expressed in Eqs. (7), (8), and (9) (coded values of the variables) represent the fucoidan yield $\left(Y_{1}\right)$, alga degradation $\left(Y_{2}\right)$, and total sugar yield in the liquor after extraction $\left(Y_{3}\right)$, as a function of the temperature $\left(x_{1}\right)$ and reaction time $\left(x_{2}\right)$ used during the AH. Such models were established with high coefficient of determination $R^{2}$ being able to explain between 84 and $97 \%$ of the responses variations.

$$
Y_{1}=15.18+0.59 x_{1}-5.43 x_{1}^{2}+0.32 x_{2}-5.54 x_{2}^{2}-1.62 x_{1} x_{2}\left(R^{2}=0.84\right)
$$

$Y_{2}=44.46-12.00 x_{1}+4.25 x_{1}^{2}-12.62 x_{2}+7.34 x_{2}^{2}-4.68 x_{1} x_{2} \quad\left(R^{2}=0.97\right)$

$Y_{3}=13.86+2.10 x_{1}-3.25 x_{1}^{2}+3.62 x_{2}^{2}-1.82 x_{2}^{2}-0.38 x_{1} x_{2} \quad\left(R^{2}=0.91\right)$

Figure 2 shows the alga structure before and after the AH process under the optimized conditions $\left(180^{\circ} \mathrm{C}\right.$ for $\left.20 \mathrm{~min}\right)$. As can be seen, the original (untreated) sample exhibited a rigid and ordered surface (Fig. 2a), which was modified after the AH process (Fig. 2b), becoming more porous and rough due to the removal of components from this structure. The TGA profiles of these samples (untreated and AHtreated alga) (Fig. 3) presented similar behavior, with three stages in the degradation pathway. The first stage $\left(<215^{\circ} \mathrm{C}\right)$ basically corresponds to dehydration of the sample; the second one $\left(215-490^{\circ} \mathrm{C}\right)$ consists in the devolatilization of the sample, and the third stage $\left(>470^{\circ} \mathrm{C}\right)$ corresponds to the decomposition region, with the remaining mass at the end of this stage being correspondent to the ash (mineral) content in the sample. High mineral content $(\sim 26 \% w / w)$ was present in the untreated alga, and a considerable amount of this fraction $(\sim 17 \% w / w)$ remained in the alga after the $\mathrm{AH}$ process. These results allow concluding that the $\mathrm{AH}$ process was more selective for the extraction of fucoidan than minerals from $F$. vesiculosus.

After optimizing the $\mathrm{AH}$ conditions, a sequential extraction process was evaluated as a strategy to maximize the fucoidan yield. By using this sequential process of $\mathrm{AH}$, low fucoidan yield $(4.47 \% \mathrm{w} / \mathrm{w})$ was obtained in the second extraction step. This strategy was then considered unviable, since the involved energy costs would not justify the little increase in the extraction yield.

\section{Characterization of the extracted fucoidans}

\section{Chemical composition}

Chemical composition of fucoidans significantly varies according to species, growth conditions, and extraction procedure, and for this reason, elucidating the chemical composition of polysaccharide's samples is very important in order to understand the influence of extraction processing on extractive products. The fucoidan samples obtained in the current study presented a heterogeneous structure mainly composed of fucose and minor proportions of galactose (Table 3). In most of the cases, the concentration of fucose was higher than $75 \%$ mol. Presence of other monosaccharides including xylose and glucose was not verified in any fucoidan sample.

High sulfate content $(>20 \%)$ was found in practically all the recovered fucoidans (Table 3 ). This is an advantageous aspect since sulfate groups have been reported to present important biological functions such as anti-HIV activity; and such activity is potentially increased when the sulfate content is increased (Schaeffer and Krylov 2000). Additionally, all the samples presented a ratio between total sugars and sulfate content $\left(\mathrm{TS} / \mathrm{SO}_{3}\right)$ higher than $1 / 0.5 \mathrm{mg}$ $\mathrm{TS} / \mathrm{mg} \mathrm{SO}_{3}$ and small quantities of proteins and phenolic compounds (Table 3). As a whole, chemical composition of the recovered fucoidan samples is comparable to other reports of sulfated fucans obtained from different sources using different extraction procedures such as sequential extraction of $F$. vesiculosus and $A$. nodosum by $\mathrm{CaCl}_{2}$ and $\mathrm{HCl}$ (Rioux et al. 2007), hydrothermal (autoclaving) hydrolysis of Laminaria japonica (Wang et al. 2009), extraction of L. cichorioides by $\mathrm{HCl}$ (Anastyuk et al. 2010), and microwave-assisted extraction of $F$. vesiculosus (Rodriguez-Jasso et al. 2011). In these cases, fucoidan was also mainly constituted by fucose (with minor amounts of galactose and/or manose) and presented sulfate contents varying between 20 and $30 \% \mathrm{w} / \mathrm{w}$. 
FTIR analysis

FTIR spectra of the fucoidan recovered under the optimized AH conditions, as well as other sulfated fucans samples extracted by AH (Fig. 4), showed typical absorption bands of fucoidans. IR bands at $1,200-970 \mathrm{~cm}^{-1}$ are mainly caused by the $\mathrm{C}-\mathrm{C}$ and $\mathrm{C}-\mathrm{O}$ stretching vibrations in the pyranoid ring and $\mathrm{C}-\mathrm{O}-\mathrm{C}$ stretching of the glycosidic bonds. Intense absorption in this region is common for polysaccharides. However, the absorption band at $1,240-1,255 \mathrm{~cm}^{-1}$ ( $\mathrm{S}=\mathrm{O}$ stretching) confirms the presence of sulfate in the recovered polysaccharides. The band at $840 \mathrm{~cm}^{-1}$ suggests a complex pattern of substitution of $\alpha$-linked L-fucopyranose at the axial C-4 position, whereas those at $833-820 \mathrm{~cm}^{-1}$ are associated to low amounts of substitution at the equatorial C-2 and C-3 position (Marais and Joseleau 2001; Wang et al. 2010).

\section{Thermal analysis}

TGA and DSC curves of fucoidan extracted under the optimized AH conditions are shown in Fig. 5. Similar profile for sulfated fucans is reported by Rodriguez-Jasso et al. (2011); however, in the present study, the volatile matter evolution for AH-fucoidan presented a constant decrease of mass without showing the stationary stage in the decomposition region. This fact suggests that the use of higher temperature $\left(>600^{\circ} \mathrm{C}\right)$ would be required to reach this stage. In any way, it is possible to verify that the fucoidan sample contained low quantity of mineral compounds (sulfates, phosphates, and carbonates).

In brief, autohydrolysis process was a suitable technology for extraction of sulfated polysaccharides from $F$. vesiculosus. The use of this technology brings important advantages from economical and environmental viewpoints since when compared to conventional extraction procedures, the autohydrolysis method is more environmentally friendly (it does not require the use of chemical solvent and generates less waste). The current study revealed that the fucoidan yield as well as the fucose and sulfate contents in the polysaccharide were affected by the temperature and reaction time used for autohydrolysis. Optimization of the extraction conditions was a useful strategy to maximize the fucoidan yield $(\sim 16.5 \% \mathrm{w} / \mathrm{w})$.

Acknowledgments R.M. Rodríguez-Jasso would like to thank the Mexican Science and Technology Council (CONACYT, Mexico) for Ph.D. fellowship support (grant number 213592/308679). The authors also thank Professor Isabel Sousa Pinto, Rita Araújo PhD from CIIMAR, University of Porto, and Bartolomeu de Souza PhD for the collaboration during the selection and collection of the seaweed used in this study.

\section{References}

Anastasakis K, Ross AB, Jones JM (2011) Pyrolysis behaviour of the main carbohydrates of brown macro-algae. Fuel 90:598-607

Anastyuk SD, Shevchenko NM, Nazarenko EL, Imbs TI, Gorbach VI, Dmitrenok PS, Zvyagintseva TN (2010) Structural analysis of a highly sulfated fucan from the brown alga Laminaria cichorioides by tandem MALDI and ESI mass spectrometry. Carbohydr Res 345:2206-2212

Berteau O, Mulloy B (2003) Sulfated fucans, fresh perspectives: structures, functions, and biological properties of sulfated fucans and an overview of enzymes active toward this class of polysaccharide. Glycobiology 13:29R-40R

Bhakuni DS, Rawat DS (2005) Bioactive metabolites of marine algae, fungi and bacteria. In: Bhakuni DS, Rawat DS (eds) Bioactive marine natural products. Springer, New York, pp $1-25$

Bradford MM (1976) A rapid and sensitive method for the quantitation of microgram quantities of protein utilizing the principle of protein-dye binding. Anal Biochem 72:248-254

Dodgson KS (1961) Determination of inorganic sulphate in studies on the enzymic and non-enzymic hydrolysis of carbohydrate and other sulphate esters. Biochem J 78:312-319

Duarte ME, Cardoso MA, Noseda MD, Cerezo AS (2001) Structural studies on fucoidans from the brown seaweed Sargassum stenophyllum. Carbohydr Res 333:281-293

Ellouali M, Boissonvidal C, Durand P, Josefonvicz J (1993) Antitumor activity of low molecular weight fucans extracted from brown seaweed Ascophyllum nodosum. Anticancer Res 13:2011-2019

Garrote G, Domínguez H, Parajó JC (1999) Hydrothermal processing of lignocellulosic materials. Holz Roh- Werkst 57:191202

Imbs TI, Krasovskaya NP, Ermakova SP, Makarieva TN, Shevchenko NM, Zvyagintseva TN (2009) Comparative study of chemical composition and antitumor activity of aqueous-ethanol extracts of brown algae Laminaria cichorioides, Costaria costata and Fucus evanescens. Russ J Mar Biol 35:164-170

Kusaykin M, Bakunina I, Sova V, Ermakova S, Kuznetsova T, Besednova N, Zaporozhets T, Zvyagintseva T (2008) Structure, biological activity, and enzymatic transformation of fucoidans from the brown seaweeds. Biotechnol J 3:904915

Lordan S, Ross RP, Stanton C (2011) Marine bioactives as functional food ingredients: potential to reduce the incidence of chronic diseases. Mar Drugs 9:1056-1100

Ludwig TG, Goldberg HJV (1954) The anthrone method for the determination of carbohydrates in foods and in oral rinsing. $J$ Dent Res 35:90-94

Mandal V, Mohan Y, Hemalatha S (2007) Microwave assisted extraction-an innovative and promising extraction tool for medicinal plant research. Pharmacog Rev 1:7-18

Marais MF, Joseleau JP (2001) A fucoidan fraction from Ascophyllum nodosum. Carbohydr Res 336:155-159

Mestechkina NM, Shcherbukhin VD (2010) Sulfated polysaccharides and their anticoagulant activity: a review. Appl Biochem Microbiol 46:267-273

O'Sullivan L, Murphy B, McLoughlin P, Duggan P, Lawlor PG, Hughes H, Gardiner GE (2010) Prebiotics from marine macroalgae for human and animal health applications. Mar Drugs 8:2038-2064

Overend RP, Chornet E (1987) Fractionation of lignocellulosics by steam-aqueous pretreatments. Philos Trans R Soc Lond A 321:523-536 
Queiroz KCS, Medeiros VP, Queiroz LS, Abreu LRD, Rocha HAO, Ferreira CV, Jucá MB, Aoyama H, Leite EL (2008) Inhibition of reverse transcriptase activity of HIV by polysaccharides of brown algae. Biomed Pharmacother 62:303-307

Rioux LE, Turgeon SL, Beaulieu M (2007) Characterization of polysaccharides extracted from brown seaweeds. Carbohydr Polym 69:530-537

Rodriguez-Jasso RM, Mussatto SI, Pastrana L, Aguilar CN, Teixeira JA (2011) Microwave-assisted extraction of sulfated polysaccharides (fucoidan) from brown seaweed. Carbohydr Polym 86:1137-1144

Ross AB, Jones JM, Kubacki ML, Bridgeman T (2008) Classification of macroalgae as fuel and its thermochemical behavior. Bioresource Technol 99:6494-6504

Schaeffer DJ, Krylov VS (2000) Anti-HIV activity of extracts and compounds from algae and cyanobacteria (Review). Ecotoxicol Environ Saf 45:208-227
Skriptsova AV, Shevchenko NM, Zvyagintseva TN, Imbs TI (2010) Monthly changes in the content and monosaccharide composition of fucoidan from Undaria pinnatifida (Laminariales, Phaeophyta). J Appl Phycol 22:79-86

Wang J, Liu L, Zhang Q, Zhang Z, Qi H, Li P (2009) Synthesized oversulphated, acetylated and benzoylated derivatives of fucoidan extracted from Laminaria japonica and their potential antioxidant activity in vitro. Food Chem 114:1285-1290

Wang J, Guo H, Zhang J, Wang X, Zhao B, Yao J, Wang Y (2010) Sulfated modification, characterization and structure-antioxidant relationships of Artemisia sphaerocephala polysaccharides. Carbohydr Polym 81:897-905

Yang C, Chung D, You S (2008) Determination of physicochemical properties of sulphated fucans from sporophyll of Undaria pinnatifida using light scattering technique. Food Chem 111:503-507 